\title{
SEGURIDAD, TERRITORIO, POBLACIÓN
}

Autor: Michel Foucault

Curso en el Collége de France (1977-1978).

Edición establecida por Michel Senellart, bajo la Dirección de Francois Ewald y Alessandro Fontana.

Primera Edición en Francés 2004,

Segunda reimpresión en español, 2007. Traducido por Horacio Pons, Editorial Fondo de Cultura Económica, Buenos Aires Argentina, 2007.

Comentario: Lisandro Silva Arriola ${ }^{1}$

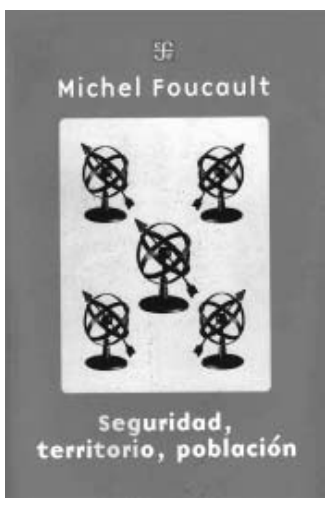

En épocas de crisis como la actual, es creciente la sensación generalizada de agotamiento de la cuestión pública y las necesarias redefiniciones en cuestiones relacionadas con el estado y su rol en las políticas de desarrollo. Se abre una oportunidad para la revisión de las políticas públicas, y efectuar un necesario proceso de evaluación sobre todo lo obrado a la fecha, respecto de la gestión pública y políticas implementadas en el modelo de desarrollo basado en el mercado. En los debates académicos, políticos y profesionales, ya no es un tabú plantear la necesidad de "revisar el modelo" o "regular el mercado", pero no sólo con la voluntad de hacer pequeños ajustes, sino que en el sentido de revisar la verdadera viabilidad de mantener el estado de cosas actual, con una gestión del estado subsidiario que arroja además evidentes síntomas de agotamiento en el ejercicio del poder de las coaliciones políticas que lo sustentan, y una población que crecientemente plantea su malestar e insatisfacción frente a políticas públicas que no los identifica, reflejado a través de movimientos sociales cada vez más activos e influyentes en las decisiones de políticas públicas.

En este contexto, la obra de Michel Foucault adquiere una vigencia notable, pues a partir de la década de los setentas se centra en el análisis de las cuestiones del poder, el rol del estado y los sistemas de pensamiento que subyacen al diseño de las políticas públicas dominados principalmente por la economía política. Foucault es un filósofo contemporáneo comprometido con la sociedad en la

1 Arquitecto, Magíster en Urbanismo U. de Chile, correo electrónico: lisandro.silva@usm.cl 
que vivió y con la función política del intelectual en la búsqueda de respuestas a las cuestiones principales que ésta le presenta. En la Revista ESPIRIT, del año 1968, Foucault centraba este rol del intelectual en un "análisis que introduce la opresión del sistema y la discontinuidad en la historia del pensamiento".

Sistemas públicos que se inventan para el bienestar de la población y que terminan oprimiéndola; historia del pensamiento que individualiza discursos que se construyen en una pluralidad de disciplinas con distintos orígenes y desarrollo en la historia. Unidades de pensamiento que se mantienen a pesar de tantos errores, olvidos, metamorfosis en forma obstinada, como la economía por ejemplo: ¿Es posible sostener que es la misma economía la que va desde los fisiócratas hasta Keynes o Milton Friedman? Otras disciplinas están en constante cambio, como la sociología y la psicología, que -según Foucaultdesde su nacimiento no han cesado de recomenzar. La cuestión de la racionalidad del Estado se relaciona entonces con las disciplinas que concurren al pensamiento que se despliega en su acción. El método de análisis es el de la Arqueología que permite explorar las capas subyacentes de las estructuras de pensamiento evidenciadas en la superficie actual.

Filósofo, historiador y psicólogo, Foucault admitía como única denominación la de "Arqueólogo", en su empeño por explicar la cultura desde los elementos más profundos subyacentes a las capas de la realidad actual. Según esta perspectiva, es interesante notar la falta de presencia de las disciplinas de las ciencias humanas en el diseño de las políticas públicas en nuestro país, prevaleciendo casi exclusivamente la economía en todos los ámbitos de la realidad social.

El libro corresponde a la recopilación del curso seguridad, territorio, población, dictado entre enero y abril de 1978 en el Colegio de Francia. Esboza lo que Foucault denomina una "historia de las tecnologías de seguridad" aplicadas a la sociedad occidental, a través del estudio de los mecanismos mediante los cuales en el siglo XVIII la especie humana ingresó en lo que el autor denomina "una estrategia general de poder".

El curso establece una génesis de un saber político que pone en el centro de sus preocupaciones la noción de población y los mecanismos que permitan asegurar su regulación. A través del análisis histórico se muestra, más que una mutación del Estado desde el "Estado Territorial" medieval a un "Estado de Población" que surge en el siglo XIX, la forma en que el estado cambia a través de los desplazamientos en el acento y objetivos, producto de nuevos problemas y nuevas técnicas a aplicar, siguiendo como hilo conductor la noción de "gobierno", en cuanto a los medios y procedimientos puestos en juego para ocuparse en una sociedad dada: el "gobierno de los hombres".

Estudiando los primeros siglos de la era cristiana, desde las primeras clases de 1978, desarrolla el proyecto de la 
construcción de la historia de la "gubernamentalidad" a través de las formas de experiencia y racionalidad que organizan el poder sobre la vida de las personas en occidente, desplazando su interés inicial sobre el "Biopoder" hacia las cuestiones del gobierno y la noción de "gubernamentalidad". A lo largo del curso, Foucault evidencia una nueva tecnología de poder surgida en el siglo XVIII y sus componentes, cuyo objeto es la población y aspira a lograr un "equilibrio global", es decir, la "seguridad del conjunto respecto de sus peligros internos". De la misma forma, el autor contrapone a esta tecnología de seguridad, los mecanismos mediante los cuales el "soberano" hasta la edad clásica, buscaba garantizar la seguridad de su territorio. La investigación se desarrolla así, sobre la base de dos polos antitéticos: Territorio y Población.

A pesar de investigar la sociedad europea, las preguntas de investigación que surgen del curso son pertinentes a nuestras sociedades americanas cuyos estados nacen de estructuras colonialistas de los siglos XVII y XVIII. ¿Cómo y cuándo se pasó de la soberanía del territorio a la regulación de las poblaciones? ¿De qué manera afecta esa transformación el plano de las prácticas gubernamentales? ¿Qué nuevas racionalidades surgen y rigen las prácticas gubernamentales de allí en adelante?

Estas preguntas de investigación revelan la tesis central del curso, es decir, ver si a través de la historia de las tecnologías de seguridad, se puede postular la existencia de una "sociedad de seguridad". De esta forma, Foucault pone de relieve progresivamente el concepto de "gobierno" a través del análisis de los dispositivos de seguridad en relacionados con la población. Gobierno, más allá de su concepto tradicional de "autoridad pública", adquiere poco a poco un valor que designa las técnicas específicas de manejo de las poblaciones, principalmente en sus inicios, bajo el influjo del concepto fisiocrático (económico) de "gobierno económico".

De esta forma, el triángulo problemático inicial de seguridad-territorio-población propio de las sociedades pre-industriales, que se planteaba como marco de referencia de investigación, es sustituido por la triada seguridad-población-gobierno, cuyo sentido es a la vez histórico y político, con extraordinaria vigencia en el diagnóstico del presente.

La reflexión iniciada por Foucault a fines de los setentas sobre la racionalidad gubernamental moderna, es partícipe principalmente del auge de un pensamiento progresista propio del contexto histórico, político e intelectual en el que se inscriben los cursos, que toma distancia del estructuralismo político y abre nuevas cuestiones relacionadas con la vida cotidiana, la situación de las mujeres, la autogestión, etc. Por otro lado, Foucault plantea los conceptos de "biopoder" y "biopolítica" para explicar los mecanismos de "defensa de la sociedad", que a partir del siglo XIX se plantean en términos 
de "guerra interna" contra los peligros originados en el propio cuerpo social. A partir de su obra, "La voluntad de saber", definirá población como "masa global", afectada por procesos de conjunto que son propios de la vida, como el nacimiento, la muerte, la reproducción, la enfermedad, etc., tal como aparece en el curso de esta obra.

Foucault plantea un programa de investigación en políticas públicas totalmente vigente: que permite entrar en problemas que subyacen en la racionalidad de las prácticas gubernamentales. ¿Qué problemas arrastran políticas diseñadas en diversos campos de la acción pública, sobre la base casi exclusiva de criterios económicos? ¿Por qué no se integran en los diagnósticos y técnicas a aplicar en los problemas de la sociedad, los aportes de distintas disciplinas de las ciencias humanas?

El término "gobierno" como "gobierno económico", en la actualidad toma el sentido restringido de "arte de ejercer el poder de la forma de la economía", mediante lo cual el liberalismo económico sería un "arte de gobernar", como forma de racionalidad propia de los dispositivos de regulación biopolítica. De esta forma, los problemas de estado, las razones de estado, son problemas de gobierno, más que problemas de la población.

Observando desde este marco de referencia, la configuración de una necesaria reforma urbana y de las políticas de vivienda en nuestro país: ¿Cuáles serían los elementos que permitirían superar las prácticas gubernamentales orientadas a la aplicación exclusiva de tecnologías de seguridad en el hábitat residencial? ¿Qué factores de la racionalidad del estado actual no permiten incorporar a la población en el diseño de políticas públicas de vivienda? ¿Qué prácticas gubernamentales no permiten incorporar elementos de satisfacción habitacional, la vida cotidiana, inclusión social, etc., en el diseño de las políticas sobre el hábitat residencial?

A partir del hábitat residencial se abre un amplio programa de investigación en ciencias sociales, economía política, ciencias políticas y urbanismo, que permitan reorientar la acción del Estado y el diseño de políticas públicas en el campo particular el desarrollo urbano y del hábitat residencial, volviendo el foco hacia los nuevos temas de la sociedad actual, en una estrategia de inclusión que permita el aporte de las distintas ciencias humanas planteando nuevos conceptos, diagnósticos y tecnologías de aplicación a los problemas actuales. Los movimientos sociales son quizás la forma espontánea de canalización de las demandas, frente a un Estado preocupado del gobierno, que no son escuchadas y dimensionadas adecuadamente por el sistema público y político.

Foucault nos plantea un camino a explorar desde la Filosofía, como la definió él mismo: "la política de la verdad". 